Published in final edited form as:

Obes Surg. 2012 August ; 22(8): 1263-1267. doi:10.1007/s11695-012-0656-6.

\title{
Accelerated Gastric Emptying but No Carbohydrate Malabsorption 1 Year After Gastric Bypass Surgery (GBP)
}

\author{
Gary Wang, \\ New York Obesity Nutrition Research Center, New York, NY, USA \\ St. Luke's Roosevelt Hospital Center, New York, NY, USA
}

Keesandra Agenor,

New York Obesity Nutrition Research Center, New York, NY, USA

St. Luke's Roosevelt Hospital Center, New York, NY, USA

\section{Justine Pizot,}

New York Obesity Nutrition Research Center, New York, NY, USA

Donald P. Kotler,

Division of Gastroenterology, Department of Medicine, St. Luke's Roosevelt Hospital Center, New York, NY, USA

St. Luke's Roosevelt Hospital Center, New York, NY, USA

Columbia University College of Physicians and Surgeons, 1111 Amsterdam Avenue, R-1034, New York, NY 10025, USA

\section{Yaniv Harel,}

New York Obesity Nutrition Research Center, New York, NY, USA

\section{Bart J. Van Der Schueren,}

New York Obesity Nutrition Research Center, New York, NY, USA

\section{Iliana Quercia,}

New York Obesity Nutrition Research Center, New York, NY, USA

\section{James McGinty, and}

Division of Minimally Invasive Surgery, Department of Surgery, St. Luke's Roosevelt Hospital Center, New York, NY, USA

St. Luke's Roosevelt Hospital Center, New York, NY, USA

Columbia University College of Physicians and Surgeons, 1111 Amsterdam Avenue, R-1034, New York, NY 10025, USA

\section{Blandine Laferrère}

New York Obesity Nutrition Research Center, New York, NY, USA

Division of Endocrinology and Diabetes, Department of Medicine, St. Luke's Roosevelt Hospital Center, New York, NY, USA

St. Luke's Roosevelt Hospital Center, New York, NY, USA

\footnotetext{
(C) Springer Science+Business Media, LLC 2012

Correspondence to: Blandine Laferrère, bbl14@ columbia . edu.

Disclosures The authors have no competing interests.
} 
Columbia University College of Physicians and Surgeons, 1111 Amsterdam Avenue, R-1034, New York, NY 10025, USA

Blandine Laferrère: bbl14@columbia.edu

\section{Abstract}

Background-Following gastric bypass surgery (GBP), there is a post-prandial rise of incretin and satiety gut peptides. The mechanisms of enhanced incretin release in response to nutrients after GBP is not elucidated and may be in relation to altered nutrient transit time and/or malabsorption.

Methods-Seven morbidly obese subjects $\left(\mathrm{BMI}=44.5 \pm 2.8 \mathrm{~kg} / \mathrm{m}^{2}\right.$ ) were studied before and 1 year after GBP with a $\mathrm{D}$-xylose test. After ingestion of $25 \mathrm{~g}$ of $\mathrm{p}^{-x y l o s e}$ in $200 \mathrm{~mL}$ of noncarbonated water, blood samples were collected at frequent time intervals to determine gastric emptying (time to appearance of $\mathrm{p}_{\mathrm{D}} \mathrm{xylose}$ ) and carbohydrate absorption using standard criteria.

Results-One year after GBP, subjects lost $45.0 \pm 9.7 \mathrm{~kg}$ and had a BMI of $27.1 \pm 4.7 \mathrm{~kg} / \mathrm{m}^{2}$. Gastric emptying was more rapid after GBP. The mean time to appearance of ${ }_{\mathrm{b}}$-xylose in serum decreased from $18.6 \pm 6.9 \mathrm{~min}$ prior to GBP to $7.9 \pm 2.7 \mathrm{~min}$ after GBP $(p=0.006)$. There was no significant difference in absorption before (serum $\mathrm{D}$-xylose concentrations $=35.6 \pm 12.6 \mathrm{mg} / \mathrm{dL}$ at 60 min and $33.9 \pm 9.1 \mathrm{mg} / \mathrm{dL}$ at $180 \mathrm{~min}$ ) or 1 year after GBP (serum $\mathrm{D}-\mathrm{xylose}=31.5 \pm 18.1 \mathrm{mg} / \mathrm{dL}$ at 60 $\min$ and $27.2 \pm 11.9 \mathrm{mg} / \mathrm{dL}$ at $180 \mathrm{~min}$ ).

Conclusions-These data confirm the acceleration of gastric emptying for liquid and the absence of carbohydrate malabsorption 1 year after GBP. Rapid gastric emptying may play a role in incretin response after GBP and the resulting improved glucose homeostasis.

\section{Keywords}

Bariatric surgery; Gastric bypass; Gastric emptying; Carbohydrate absorption; D-xylose

\section{Introduction}

As a result of gastric bypass surgery (GBP), the post-prandial release of satiety and incretin gut peptides such as GLP1 [1, 2], PYY [3], or oxyntomodulin [4] is enhanced. The mechanism of the increased release of gut peptides in response to nutrients after GBP may involve accelerated nutrient transit time [1] or altered nutrient sensing [5].

Physiologically, gastric emptying (GE) is an important determinant of blood glucose [6] and of incretin levels [7]. Accelerated nutrient emptying after total gastrectomy increases GLP-1 release in response to an oral challenge [8]. GE is accelerated after GBP $[9,10]$ and the enhanced GLP-1 response to a liquid mixed meal is related to gastric emptying [1].

Maldigestion of carbohydrates with possible altered nutrient sensing is implicated in incretin release [5, 11]. Little is known about nutrient absorption after GBP surgery. Although vitamin and mineral deficiencies are often reported, indicating malabsorption of those micronutrients [12], malabsorption of macronutrients may not be significant [13]. The aim of the present study was to assess the change of GE and of carbohydrate absorption after GBP. We hypothesized that GE for liquid would be accelerated. We also hypothesized the presence of some degree of carbohydrate malabsorption 1 year after GBP. 


\section{Materials and Methods}

\section{Subjects}

Seven morbidly obese individuals were recruited among patients who presented for bariatric surgery at St Luke's Roosevelt Hospital. All participants provided informed consent prior to enrolment in the study.

\section{Study Design}

Patients were studied before and 1 year after GBP. All participants underwent laparoscopic GBP as described previously [2]. The jejunum was divided $30 \mathrm{~cm}$ from the ligament of Treitz and anastomosed to a $30-\mathrm{mL}$ proximal gastric pouch. The jejunum was reanastomosed $150 \mathrm{~cm}$ distal to the gastro-jejunostomy.

\section{D-Xylose Test}

The subjects ingested $25 \mathrm{~g}$ of $\mathrm{D}-\mathrm{xylose}$ in $200 \mathrm{~mL}$ water after an overnight fast. Blood samples were collected at $0,5,10,20,30,60,90,120$, and $180 \mathrm{~min}$ via a peripheral intravenous catheter into chilled sodium fluoride-potassium oxalate tubes. Samples were centrifuged at $1,620 \mathrm{~g}$ for $15 \mathrm{~min}$ at $4^{\circ} \mathrm{C}$ to separate the plasma. Plasma samples were stored at $-70^{\circ} \mathrm{C}$ until analysis. Serum $\mathrm{D}$-xylose levels, after ingestion of a solution of $\mathrm{D}$-xylose, were used as an indirect measure of gastric emptying (GE) as defined by the time to appearance of detectable ${ }_{\mathrm{D}}$-xylose concentration in serum, at least $5 \mathrm{mg} / \mathrm{dL}$ above baseline levels [14]. Carbohydrate malabsorption was determined using standard criteria: at $60 \mathrm{~min}$ D-xylose concentrations $<20 \mathrm{mg} / \mathrm{dL}$ and at $180 \mathrm{~min}<22.5 \mathrm{mg} / \mathrm{dL}$ [15]. Symptoms (nausea, vomiting, diarrhea, diaphoresis) and vital signs were monitored during the 3 -h test to assess potential dumping syndrome after ingestion of the $\mathrm{D}_{\mathrm{D}}$-xylose drink.

D-xylose levels were measured by colorimetric assay [16]. The intra-assay coefficient of variation was less than $10 \%$ for $\mathrm{D}$-xylose concentrations ranging from 5 to $70 \mathrm{mg} / \mathrm{dL}$. Glucose concentrations were measured at the bedside by the glucose oxidase method (Analox Glucose Analyzer; Analox Instruments, Lunenburg, MA, USA). All assays were performed at the New York Obesity Research Nutrition Center.

\section{Statistical Analysis}

Paired $t$-tests were used to assess changes in outcome variables before and after GBP. Pitman's tests were used to compare correlated variances (square of the $\operatorname{SD}\left(\sigma^{2}\right)$ ) to quantify changes in variability over time. SPSS 18 was used for data analysis. Data are represented as mean \pm SD. $P$-values $<0.05$ were considered to be statistically significant.

\section{Results}

The mean age of participants $(n=7)$ was $38.7 \pm 13.0$ years and pre-GBP BMI was $44.5 \pm 2.8$ $\mathrm{kg} / \mathrm{m}^{2}$ (Table 1). Three subjects had recently been diagnosed with type 2 diabetes and had a mean glycated hemoglobin (HbA1C) of $6.2 \pm 0.3 \%$.

Weight and BMI decreased significantly 1 year after GBP as expected, with a mean weight loss at 1 year of $45.0 \pm 9.7 \mathrm{~kg}$ (Table 1). For subjects with diabetes, the HbA1C normalized at 1 year $(6.4 \pm 0.5$ to $5.6 \pm 0.1 \%)$. Four of the seven subjects experienced minor to moderate symptoms of nausea and upset stomach, likely in relation to dumping after ingestion of $\mathrm{D}^{-}$ xylose after GBP. The time to appearance of $\mathrm{D}$-xylose in serum, used as an indirect measure of GE, decreased from 18.6 \pm 6.9 min prior to GBP to $7.9 \pm 2.7 \mathrm{~min}$ after GBP ( $p=0.006$ ), showing acceleration of liquid emptying from the gastric pouch after GBP (Table 1; Fig. 1). 
This occurs in spite of a longer time to drink the ${ }_{\mathrm{D}}-\mathrm{xylose}$ solution. The time to drink increased from $1.5 \pm 0.9 \mathrm{~min}$ before GBP to $5.5 \pm 3.2 \mathrm{~min}$ after GBP.

As expected, none of the participants had $\mathrm{D}$-xylose malabsorption prior to GBP. Contrary to our hypothesis, there was no difference in absorption of -xylose 1 year after GBP. $\mathrm{D}$-xylose concentrations were greater than $20 \mathrm{mg} / \mathrm{dL}$ at $60 \mathrm{~min}(31.5 \pm 18.1 \mathrm{mg} / \mathrm{dL})$ and greater than $22.5 \mathrm{mg} / \mathrm{dL}$ at $180 \mathrm{~min}(27.20 \pm 12.0 \mathrm{mg} / \mathrm{dL})$.

Both GE and $\mathrm{D}_{\mathrm{D}} \mathrm{xylose}$ absorption were characterized by inter-subject variability before and after surgery. Variance in time to appearance of $\mathrm{D}$-xylose decreased significantly $(p=0.001)$ after GBP. There was a trend, though insignificant, towards increased variance of $\mathrm{D}$-xylose concentration at $60 \mathrm{~min}(p=0.098)$ and $180 \mathrm{~min}(p=0.148)$ after GBP.

\section{Discussion}

These data confirmed the accelerated gastric emptying for liquid after GBP. This is in agreement with several past studies, using either the gold standard direct scintigraphic method $[9,10,17]$ or the indirect method by acetaminophen [1] which showed that gastric emptying is accelerated for liquids following GBP. On the contrary, GE has been shown to be slower for solids after bypass $[9,10]$. Nutrient transit time is related to GLP-1 release. Accelerated nutrient emptying after total gastrectomy increases GLP-1 release in response to a solid meal challenge [8]. The incretin response to a liquid meal was also shown to be related to nutrient transit time 6 weeks after GBP [1]. Similarly, accelerated transit of a liquid meal was implicated in the enhanced incretin response that led to hyperinsulinemic hypoglycemia after GBP [18].

We hypothesized that the bypass procedure and shunting of the duodenum, with delayed and/or maldigestion of the chyme, would result in malabsorption of carbohydrate, as assessed by $\mathrm{p}$-xylose test. Contrary to our hypothesis, our data demonstrate no difference in the total absorption of carbohydrate 1 year after GBP in our cohort. $\mathrm{D}$-xylose absorption is passive at the concentrations reached with a 25-g dose [19]. Serum $\mathrm{D}$-xylose concentration is therefore more a measure of small bowel surface area, and these results suggest that a substantial amount of surface area for absorption remains after gastric bypass. Although vitamin and micronutrient malabsorption are frequently reported and can be clinical challenges [12, 20, 21], there are few reports of macronutrient malabsorption after GBP. Fecal fat excretion has been shown to be increased to an average of greater than $6 \mathrm{~g}$, meeting clinical criteria for steatorrhea, at 6 months and 1 year after GBP [22]. Odstrcil et al. identified no significant changes in fat, protein, and carbohydrate absorption in nine patients 5 and 14 months after GBP [13]. However, there is a paucity of data on carbohydrate absorption after bypass surgery. Most dietary carbohydrate should be well absorbed in the Roux limb after digestion by mucosal disaccharidases and uptake via sodium-glucose cotransport. Salivary amylase can digest starches in the mouth and gastric pouch, and the digestive products could then be absorbed in the Roux limb. Further, carbohydrate digestion and absorption would occur in the common channel, which contains the pancreatic amylase [23]. Finally, carbohydrates not absorbed in the small intestine reach the colon, where bacteria convert them to short-chain fatty acids. These fatty acids are absorbed mostly by colonic mucosa [24]. Alteration of nutrient sensing with maldigestion and or malabsorption has been shown to alter GLP-1 release. Maldigestion of carbohydrates by the administration of acarbose, an alpha glucosidase inhibitor [5, 25], or arabinose, an intestinal sucrase inhibitor [11], increases post-prandial GLP-1 in humans.

We have previously described increase over time of the between-subject variability of the incretin response 2 years after GBP [26]. If any relation exists between incretin response and 
gastric emptying, we would expect to find similar changes in between-subject variability of gastric emptying and absorption of carbohydrates. However, the variance in time to appearance of $\mathrm{D}$-xylose decreased significantly and there was no significant change in the variance of the absorption. Future studies will have to address change in absorption rate, taking into account dietary changes.

Individual variability in gastric pouch emptying and absorption of carbohydrates may be dependent on the size of the gastro-jejunal anastomosis and of the length of the Roux and the bypassed limbs. However, neither Horowitz et al. [10] nor Naslund and Beckman [9], with scintigraphic state-of-the-art methods, showed a correlation between the size of the stomach or the gastro-jejuno asnastomosis, and the rate of gastric emptying. Gastric bypass surgery is still not a standardized procedure and there is variability in the length of the Roux-en-Y and bypassed limb from patient to patient and from surgeon to surgeon. We were careful to select patients with BMI $<50 \mathrm{~kg} / \mathrm{m}^{2}$ to ensure some homogeneity in the anatomy change induced by the surgery. For patients with BMI $>50 \mathrm{~kg} / \mathrm{m}^{2}$, the bypass is larger and may induce some element of malabsorption. We studied three patients with large BMIs (range 56.2 to $64.9 \mathrm{~kg} / \mathrm{m}^{2}$ ), and one showed malabsorption of $\mathrm{D}$-xylose 1 year after GBP (data not shown). Therefore, our data have to be interpreted with caution and it is possible that some element of malabsorption occurs after GBP. This needs to be studied in patients with larger BMIs for different nutrients and for longer periods of time after surgery as some element of gut adaptation may occur overtime [26].

Of note, about half of the patients experienced some element of discomfort, possibly related to dumping, after ingestion of $25 \mathrm{~g}$ of $\mathrm{D}$-xylose at 1 year after GBP. Dumping syndrome is caused by the rapid emptying of a hypertonic carbohydrate load into the small bowel. The discomfort could also be explained by the size of the post-GBP gastric pouch, which is significantly smaller than the volume of $\mathrm{D}$-xylose solution ingested [10]. Although dumping syndrome can be associated with abdominal pain, cramping, flushing, palpitations, diaphoresis, tachycardia, or hypotension [12], most patients experienced no or minor symptoms after ingestion of the ${ }_{\mathrm{D}}$-xylose solution at 1 year after GBP.

Our study has limitations. The small sample size and narrow range of BMI does not allow definite conclusions on the risk of carbohydrate malabsorption after GBP. In addition, Dxylose is a synthetic sugar and its absorption may not reflect the absorption of glucose or other natural sugars. A breath hydrogen test following an oral glucose load may be a better measure of carbohydrate malabsorption than serum $\mathrm{D}$-xylose [27].

Finally, carbohydrates are usually ingested as part of mixed meals, and the emptying and absorption of mixed nutrient may differ from that of isolated nutrient. We did not control for diet in the days prior to the study, either before or 1 year after GBP. It is possible that diet composition influences the results of the measurement [13]. Finally, we do not have data on GLP-1 levels in our cohort. $\mathrm{D}-\mathrm{xyl}$ lose is a weak GLP-1 secretagogue after GBP.

In summary, our data confirm accelerated GE of liquid after GBP and show no malabsorption of carbohydrate by pxylose test at 1 year after GBP in patients with BMI $<50$ $\mathrm{kg} / \mathrm{m}^{2}$ prior to GBP. Super obese (BMI $>50 \mathrm{~kg} / \mathrm{m}^{2}$ ) patients who may undergo a more invasive type of GBP with a longer Roux limb (>>150 cm) may experience carbohydrate malabsorption.

\section{Acknowledgments}

We thank our participants, the technicians from the NYONRC Hormonal Core Laboratory, Yim Dam and Ping Zhou, the GCRC-CTSA staff, Toni Colarusso for recruiting participants, and Dr. Julio Teixeira, Dr. James McGinty, and Dr. Ninan Koshy_bariatric surgeons-for allowing access to their patients for research studies. Part 
of the data were presented at the 71st Scientific Sessions of the American Diabetes Association (Diabetes 2011; 60 (Suppl. 1):A48, 174-OR), San Diego, CA, USA, 24-28 June 2011. This study was funded by grants from the American Diabetes Association-CR-7-05 CR-18 and from the NIH-R01-DK67561, PO1-DK58398, 1 UL1 RR024156-02, DK-26687, and DK-63068-05.

\section{References}

1. Morinigo R, Moize V, Musri M, et al. Glucagon-like peptide-1, peptide YY, hunger, and satiety after gastric bypass surgery in morbidly obese subjects. J Clin Endocrinol Metab. 2006; 91(5): 1735-1740. [PubMed: 16478824]

2. Laferrère $B$, Heshka $S$, Wang $K$, et al. Incretin levels and effect are markedly enhanced 1 month after Roux-en-Y gastric bypass surgery in obese patients with type 2 diabetes. Diabetes Care. 2007; 30:1709-1716. [PubMed: 17416796]

3. Olivan B, Teixeira J, Bose M, et al. Effect of weight loss by diet or gastric bypass surgery on peptide YY3-36 levels. Ann Surg. 2009; 249(6):948-953. [PubMed: 19474685]

4. Laferrère B, Swerdlow N, Bawa B, et al. Rise of oxyntomodulin in response to oral glucose after gastric bypass surgery in patients with type 2 diabetes. J Clin Endocrinol Metab. 2010; 95(8):40724076. [PubMed: 20501690]

5. Qualmann C, Nauck MA, Holst JJ, et al. Glucagon-like peptide 1 (7-36 amide) secretion in response to luminal sucrose from the upper and lower gut. A study using alpha-glucosidase inhibition (acarbose). Scand J Gastroenterol. 1995; 30(9):892-896. [PubMed: 8578189]

6. Chang J, Rayner CK, Jones KL, et al. Diabetic gastroparesis and its impact on glycemia. Endocrinol Metab Clin N Am. 2010; 39(4):745-762.

7. Chaikomin R, Doran S, Jones KL, et al. Initially more rapid small intestinal glucose delivery increases plasma insulin, GIP, and GLP-1 but does not improve overall glycemia in healthy subjects. Am J Physiol Endocrinol Metab. 2005; 289(3):E504-E507. [PubMed: 15886226]

8. Miholic J, Orskov C, Holst JJ, et al. Emptying of the gastric substitute, glucagon-like peptide-1 (GLP-1), and reactive hypoglycemia after total gastrectomy. Dig Dis Sci. 1991; 36(10):1361-1370. [PubMed: 1914756]

9. Naslund I, Beckman KW. Gastric emptying rate after gastric bypass and gastroplasty. Scand J Gastroenterol. 1987; 22(2):193-201. [PubMed: 3554493]

10. Horowitz M, Cook DJ, Collins PJ, et al. Measurement of gastric emptying after gastric bypass surgery using radionuclides. Br J Surg. 1982; 69(11):655-657. [PubMed: 7127049]

11. Krog-Mikkelsen I, Hels O, Tetens I, et al. The effects of 1-arabinose on intestinal sucrase activity: dose-response studies in vitro and in humans. Am J Clin Nutr. 2011; 94(2):472-478. [PubMed: 21677059]

12. Decker GA, Swain JM, Crowell MD, et al. Gastrointestinal and nutritional complications after bariatric surgery. Am J Gastroenterol. 2007; 102(11):2571-2580. [PubMed: 17640325]

13. Odstrcil EA, Martinez JG, Santa Ana CA, et al. The contribution of malabsorption to the reduction in net energy absorption after long-limb Roux-en-Y gastric bypass. Am J Clin Nutr. 2010; 92(4): 704-713. [PubMed: 20739420]

14. Salehi M, Vahl TP, D'Alessio DA. Regulation of islet hormone release and gastric emptying by endogenous glucagon-like peptide 1 after glucose ingestion. J Clin Endocrinol Metab. 2008; 93(12):4909-4916. [PubMed: 18827000]

15. Ehrenpreis E, Salvino M, Craig R. Improving the serum d-xylose test for the identification of patients will small intestinal malabsorption. J Clin Gastroenterol. 2001; 33(1):36-40. [PubMed: 11418788]

16. Eberts TJ, Sample RH, Glick MR, et al. A simplified, colorimetric micromethod for xylose in serum or urine, with phloroglucinol. Clin Chem. 1979; 25(8):1440-1443. [PubMed: 455682]

17. Villar HV, Wangenteen SL, Burks TF, et al. Mechanisms of satiety and gastric emptying after gastric partitioning and bypass. Surgery. 1981; 90(2):229-236. [PubMed: 7256538]

18. McLaughlin T, Peck M, Holst J, et al. Reversible hyperinsulinemic hypoglycemia after gastric bypass: a consequence of altered nutrient delivery. J Clin Endocrinol Metab. 2010; 95(4):18511855. [PubMed: 20133462] 
19. Craig R, Ehrenpreis E. d-xylose testing. J Clin Gastroenterol. 1999; 29(2):143-150. [PubMed: 10478874]

20. Alvarez-Leite JI. Nutrient deficiencies secondary to bariatric surgery. Curr Opin Clin Nutr Metab Care. 2004; 7(5):569-575. [PubMed: 15295278]

21. Malinowski SS. Nutritional and metabolic complications of bariatric surgery. Am J Med Sci. 2006; 331(4):219-225. [PubMed: 16617238]

22. Kumar R, Lieske JC, Collazo-Clavell ML, et al. Fat malabsorption and increased intestinal oxalate absorption are common after Roux-en-Y gastric bypass surgery. Surgery. 2011; 149(5):654-661. [PubMed: 21295813]

23. Layer P, Go VL, DiMagno EP. Fate of pancreatic enzymes during small intestinal aboral transit in humans. Am J Physiol. 1986; 251(4 Pt 1):G475-G480. [PubMed: 2429560]

24. Hammer HF, Fine KD, Santa Ana CA, et al. Carbohydrate malabsorption. Its measurement and its contribution to diarrhea. J Clin Invest. 1990; 86(6):1936-1944. [PubMed: 2254453]

25. Goke B, Herrmann C, Goke R, et al. Intestinal effects of alpha-glucosidase inhibitors: absorption of nutrients and enterohormonal changes. Eur J Clin Investig. 1994; 24(Suppl 3):25-30. [PubMed: 8001623]

26. Van der Schueren BJ, Homel P, Alam M, et al. Magnitude and variability of the glucagon-like peptide- 1 response in patients with type 2 diabetes up to 2 years following gastric bypass surgery. Diabetes Care. 2012; 35:42-46. [PubMed: 22124715]

27. Urita $\mathrm{Y}$, Ishihara S, Akimoto T, et al. Seventy-five gram glucose tolerance test to assess carbohydrate malabsorption and small bowel bacterial overgrowth. World J Gastroenterol. 2006; 12(19):3092-3095. [PubMed: 16718794] 


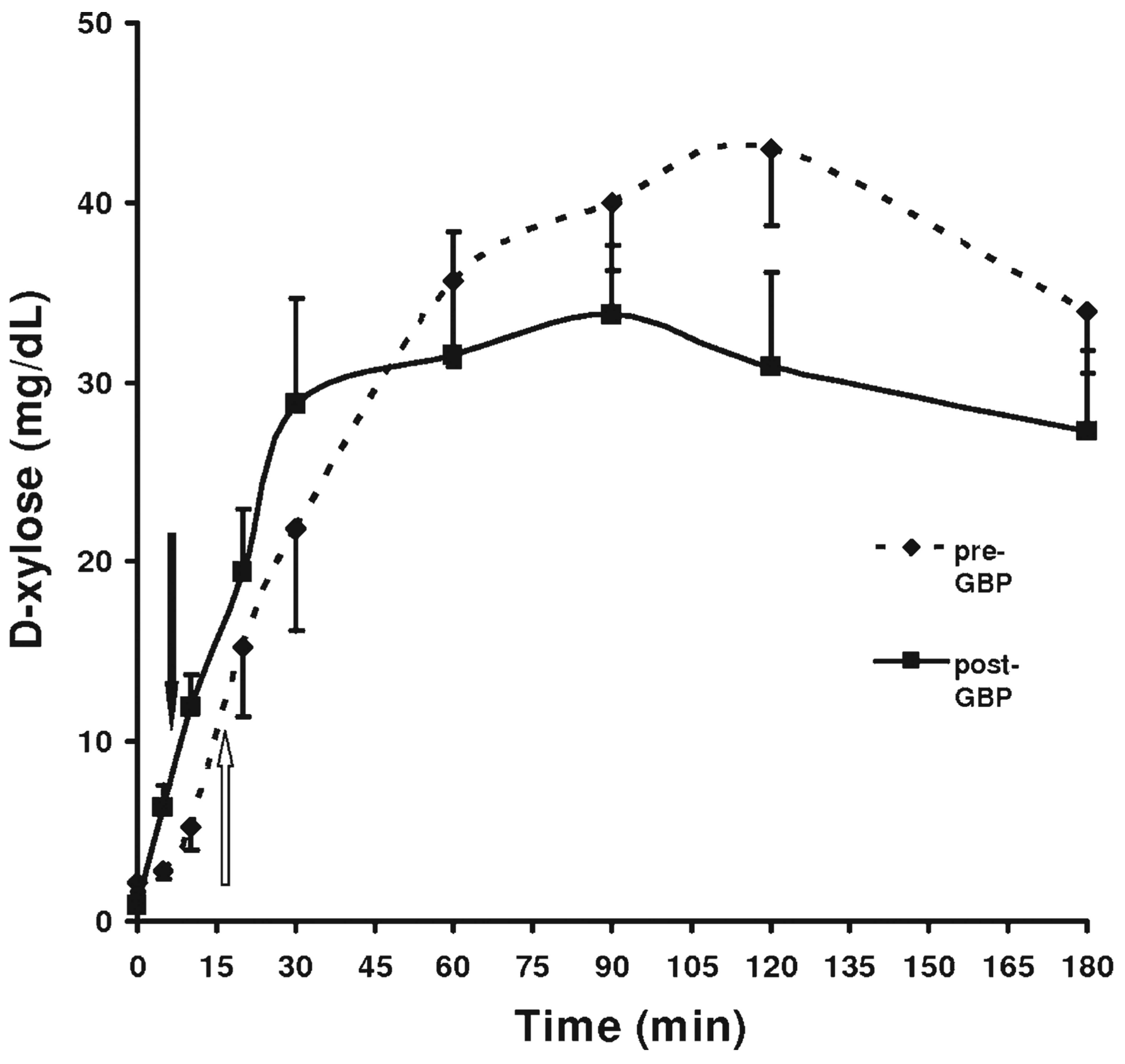

Fig. 1.

D-Xylose levels $(\mathrm{mg} / \mathrm{dL})$ are mean \pm SEM. The white arrow indicates time to appearance of serum $\mathrm{D}$-xylose pre-GBP $(18.6 \pm 6.9 \mathrm{~min})$ and the black arrow indicates time to appearance of serum $\mathrm{D}$-xylose post-GBP (7.9 $\pm 2.7 \mathrm{~min})$. Times are mean $\pm \mathrm{SD}$ 
